\title{
O CONSELHO ESCOLAR E A CONSOLIDAÇÃO DA GESTÃO DEMOCRÁTICA NA ESCOLA PÚBLICA
}

\author{
Maria Eliza Nogueira Oliveira, Tatiane Oliveira Santos Nascimento, João Gomes Moreira. \\ Universidade do Oeste Paulista - UNOESTE - Mestrado em Educação, Presidente Prudente, SP, E-mail: \\ mariaeliza oliveira@yahoo.com.br
}

\section{RESUMO}

A pesquisa apresentada neste artigo foi norteada por dois objetivos principais: identificar os desafios enfrentados pela escola pública no processo de consolidação da gestão democrática; e compreender como esses desafios poderiam ser superados na percepção dos sujeitos que compõem o universo escolar. A pesquisa foi realizada em uma escola pública estadual situada em um bairro periférico de uma cidade do interior paulista. Os dados da pesquisa foram obtidos por meio do diálogo com os sujeitos da pesquisa (pais, alunos, professores, funcionários e gestores) em encontros formativos que compuseram uma das etapas da pesquisa. Os dados foram registrados em um diário de campo e, posteriormente, analisados com apoio do método de análise de conteúdo. Os resultados apontaram como principais desafios a serem enfrentados a ausência de reflexão em torno do conceito de gestão democrática, a ausência de autonomia, a ineficiência do Conselho Escolar, o desconhecimento e a fragilidade das normas escolares.

Palavras-chave: Gestão Democrática, Participação, Autonomia, Conselho Escolar.

\section{THE SCHOOL COUNCIL AND THE CONSOLIDATION OF DEMOCRATIC MANAGEMENT IN THE PUBLIC SCHOOL}

\begin{abstract}
The research presented in this article was guided by two main objectives: to identify the challenges faced by the public school in the process of consolidating democratic management; and understand how these challenges could be overcome in the perception of the subjects that make up the school universe. The research was carried out in a state public school located in a peripheral district of a city in the interior of São Paulo. The research data were obtained through the dialogue with the research subjects (parents, students, teachers, employees and managers) in formative meetings that comprised one of the research stages. Data were recorded in a field diary and subsequently analyzed with the support of the content analysis method. The results pointed out as main challenges to be faced the absence of reflection on the concept of democratic management, lack of autonomy, inefficiency of the School Council, lack of knowledge and fragility of school rules.
\end{abstract}

Keywords: Democratic Management, Participation, Autonomy, School Council. 


\section{INTRODUÇÃO}

Os estudos críticos da educação (SAVIANI, 2008; PARO, 2016; DUARTE, 2007), defendem que uma das funções primordiais da escola pública é garantir a transmissão dos saberes historicamente acumulados, visando à formação integral de todos os cidadãos para a transformação da sociedade e a superação do sistema atual sistema capitalista responsável pelo aprofundamento da desigualdade social fruto das relações de classes. Aos adeptos desta abordagem, sem uma escola que desenvolva o saber crítico e criativo, o Estado neoliberal passa a promover, em todos os âmbitos, uma educação para a manutenção do status quo pela via da transmissão de saberes técnicos e superficiais que visam à mera formação de mão de obra para abastecer o mercado de trabalho. A escola atuaria, neste sentido, como meio eficiente de preservação do controle, como uma pequena fábrica de produção da mão de obra que ali se concentra. Distante de objetivos que conduzam os indivíduos a uma educação emancipadora para que possam acompanhar e participar da vida política, em defesa dos princípios democráticos e dos interesses da classe trabalhadora, a escola passa a atuar no sentido de estabelecer os princípios positivistas da "ordem" e do "progresso" que acabam por favorecer apenas uma camada pequena da população que detém o poder - por meio da posse dos meios de produção -, restringindo os direitos das grandes massas, inclusive, o direito à educação.

Estes dois modos de compreender a função social da escola - para a manutenção ou para a transformação do status quo -, conduzem a possíveis modelos de organização e gestão do espaço escolar que se configuram a partir dos objetivos escolares.

Compreendendo a gestão como "utilização racional dos recursos para a realização de fins determinados" (PARO, 2008, p. 18), em ambas as proposições, são apresentados modos de organizar a escola no sentido do atendimento dos interesses que pretendem alcançar por meio da formação dos indivíduos que atuarão na sociedade. Em outras palavras, a escola acaba por atuar como Aparelho Ideológico de Estado (ALTHUSSER, 1985), no sentido da manutenção dos interesses daqueles que ocupam as instâncias de poder, reproduzindo o "arbitrário cultural" que o Estado julga ser legítimo.

Numa formação social determinada, o Trabalho Pedagógico pelo qual se realiza a Ação Pedagógica dominante tem sempre uma função de manter a ordem, isto é, de reprodução da estrutura das relações de força entre os grupos ou as classes, na medida em que tende, seja pela inculcação, seja pela exclusão, a impor aos membros dos grupos ou classes dominados o reconhecimento da legitimidade da cultura dominante, e a lhes fazer interiorizar, numa medida variável, disciplinas e censuras que servem tanto melhor aos interesses, materiais ou simbólicos, dos grupos ou classes dominantes, quanto mais tomam a forma da autodisciplina e da autocensura. (BOURDIEU; PASSERON, 2011, p. 6263)

O modelo social vigente, portador de uma ideologia hegemônica, determinaria, portanto, a organização do espaço escolar, em todos os aspectos (didático-pedagógicos, curricular, administrativo, arquitetônico), para garantir a disseminação desta mesma ideologia. No caso do atual modelo de sociedade, pautado na ideologia capitalista neoliberal, a escola serviria a estes mesmos ideais e, segundo Paro (2008, p. 129), aplicaria "as normas e métodos administrativos que são específicos da empresa capitalista", baseados na divisão racional do trabalho e na hierarquia, em que as decisões se concentram nas mãos de poucos indivíduos treinados para o atendimento dos interesses do Estado que representam. Consequentemente, este modo de organização contribuiria para a reprodução das relações de classes, uma vez que não se abririam espaços de participação coletiva reservados para a apresentação de questionamentos que pudessem motivar qualquer mudança possível na estrutura escolar, pois isto levaria os indivíduos a tomarem consciência do poder da participação nas mudanças das estruturas sociais mais amplas.

Por outro lado, uma escola que assumisse a função de preparar os alunos para o exercício da cidadania, em defesa de direitos, e para a luta em busca da superação das desigualdades 
sociais, prezaria por processos de tomada de decisão democráticos, pela via da representação, do diálogo, do compromisso coletivo, em prol de objetivos que levassem em conta as necessidades e os anseios da comunidade que se veria como parte no processo de formação dos indivíduos inseridos no ambiente escolar.

[...] Quando se trata da busca de objetivos que atendam democraticamente aos interesses dos envolvidos, a forma mais razoável (até para atender ao princípio essencial da coerência entre meios e fins) é a da cooperação, em que a coordenação do trabalho é feita na forma do consentimento livre dos indivíduos envolvidos. Para que isso aconteça, seria desejável que o processo não fosse organizado de maneira a que um mande e os demais obedeçam, como tem sido na escola - à imagem e semelhança do que ocorre nas organizações do sistema econômico-produtivo em geral -, mas de uma forma que facilite o diálogo entre todos (PARO, 2016, p.66).

A partir dessas considerações, propôs-se o desenvolvimento de uma pesquisa cujo objetivo foi identificar os principais elementos necessários para a consolidação da gestão democrática na escola, assim como aqueles que dificultam o processo de construção de espaços coletivos de tomada de decisão pela via da representação, envolvendo todos os segmentos da escola. Para o alcance do objetivo proposto, escolheu-se como campo de estudo uma escola pública estadual paulista situada em um bairro periférico de uma cidade de médio porte. Optou-se por, num primeiro momento, desenvolver uma pesquisa exploratória baseada no levantamento de documentos que permitam a obtenção de dados pertinentes sobre a escola a ser estudada e seu respectivo sistema de ensino. Realizada a pesquisa exploratória, iniciou-se a pesquisa de campo em que foram investigados, por meio de observações e encontros com a equipe gestora, os docentes, discentes, funcionários e pais/responsáveis, os principais desafios enfrentados pela escola para a consolidação de espaços coletivos de tomada de decisões. Por fim, compreendida a dinâmica escolar, propôs-se a realização de uma pesquisa-ação, onde foram realizados momentos de formação com os gestores, visando à consolidação de espaços coletivos de tomada de decisão.

No limite deste artigo, serão apresentados resultados desta primeira etapa da pesquisa, em que investigou-se os limites da gestão democrática na percepção dos diferentes segmentos da escola investigada.

\section{METODOLOGIA}

Conforme já mencionado, elegeu-se, como campo de estudo, uma escola estadual do interior paulista. Esta escola já vinha vivenciando processos de intervenções realizados por pesquisadores do Programa de Pós-Graduação em Educação (PPGE) da UNOESTE desde o ano de 2015, quando se iniciou o desenvolvimento da pesquisa "Melhoria do desempenho de uma escola pública estadual: programa de desenvolvimento profissional dos gestores escolares e de professores do ciclo II do ensino fundamental mediante pesquisa-ação". Em termos gerais, o conjunto de ações realizado na escola perseguiu o objetivo comum de compreender em que medida as ações dos pesquisadores junto à comunidade têm modificado o ambiente escolar, gerando novas práticas que contribuam com o alcance das metas estabelecidas no projeto pedagógico da escola, em que se inclui o fortalecimento da Gestão Democrática, principal foco desta pesquisa ${ }^{1}$.

Com o intuito de obter respostas satisfatórias às questões norteadoras da pesquisa, propôs-se a realização de uma investigação de caráter qualitativo, voltada às "experiências e vivências dos indivíduos e grupos que participam e constroem o cotidiano escolar" (ANDRÉ, 2006, p. 37). Os dados da pesquisa foram obtidos por meio de análise documental, encontros de formação e registro contínuo das intervenções realizadas no desenvolvimento da pesquisa-ação.

\footnotetext{
${ }^{1}$ Por se tratar de pesquisa envolvendo seres humanos, o projeto foi submetido para análise do Comitê de Ética em Pesquisa (CEP) da UNOESTE e aprovado no dia 21 de junho de 2017 (PROTOCOLO no 3879).
} 
Para a fase exploratória da pesquisa, optou-se pela realização de encontros e reuniões com os diversos segmentos da escola e pelo levantamento de documentos. O diálogo traçado entre os pesquisadores e os membros da escola converteu-se em um valioso instrumento de coleta de dados que nos permitiram compreender os modos como os sujeitos percebem e significam a realidade escolar além de levantar informações consistentes que, ao serem descritas, abriram espaços para a compreensão da lógica que preside as relações que se estabelecem no interior do grupo investigado.

Ao todo, foram realizados, durante o segundo semestre de 2017, 8 encontros, sendo 1 encontro com todos os funcionários da escola, 1 encontro com os alunos membros do grêmio estudantil, 2 encontros com os pais/responsáveis dos alunos e 4 encontros com todos os professores e a equipe gestora da escola (coordenadora pedagógica e vice-diretora).

No caso dos pais, os encontros foram agendados previamente e o convite foi estendido a todos, chegando a uma média de vinte pais por encontro. Os encontros com os professores e a equipe gestora foram realizados durante as Aulas de Trabalho Pedagógico Coletivo (ATPCs), com uma média de dezessete participantes. Durante os encontros, foram lançadas questões e realizadas reflexões em torno dos princípios da gestão democrática. As reflexões foram mediadas pelos pesquisadores com base em trechos referentes à legislação educacional e a textos acadêmicos, que foram projetados em slides construídos em Power Point.

Durante o encontro, foram feitos registros em um diário de campo que, posteriormente, foram analisados com base em algumas técnicas abstraídas do método da análise de conteúdo (MAIA, 2007). As categorias foram levantadas a posteriori, considerando a frequência das respostas que emergiram durante o diálogo mediado pelos materiais já explicitados e pelas seguintes questões:

1. O que é gestão democrática?

2. A gestão democrática é importante? Por quê?

3. Esta escola possui uma gestão democrática?

4. Quais os maiores desafios para a consolidação da gestão democrática na escola?

\section{RESULTADOS}

Após o diálogo com os diferentes segmentos da escola, debruçamo-nos sobre as anotações feitas em nosso diário de campo para realização da análise. Das respostas diretas referentes às quatro questões levantadas e dos comentários que emergiram a partir do debate em torno dos materiais levados como referência, emergiram seis grandes categorias que apresentaremos brevemente: 1) Gestão Democrática; 2) Participação; 3) Conselho Escolar; 4) Autonomia Escolar; 5) Projeto Político-Pedagógico (PPP); 6) Regimento Escolar.

Com relação à primeira categoria, constatamos que não há uma clara compreensão por parte dos sujeitos da escola a respeito do que é gestão democrática. Apenas dois professores manifestaram-se a respeito, sendo um defensor da gestão democrática, devido à sua experiência quando docente no Estado do Paraná onde as "decisões eram tomadas em conjunto e encaminhadas ao sindicato quando o problema se referia ao professor", e outro crítico da gestão democrática por considerar que, no Estado de São Paulo, esta proposta está "apenas no papel", pois "tudo vem imposto da diretoria" não havendo espaço para decisões coletivas.

A respeito da participação, foram apontados vários desafios, todavia, a ênfase maior, por parte de todos os segmentos, com exceção dos alunos, recaiu sobre a "falta de tempo". Os professores e funcionários alegaram também não "serem remunerados para isso [referindo-se à extensão das horas de trabalho]", já os pais, com exceção de duas mães que disseram ter "interesse em participar mais das reuniões", ressaltaram a grande dificuldade que encontram para que sejam "dispensados do trabalho" para estar mais presente na escola. Outro pai ressaltou que o que "falta mesmo é consciência e interesse", pois "dá para fazer um esforço se quiser". Os 
alunos, por sua vez, mostraram grande interesse em participar, mas disseram "não haver abertura por parte da direção da escola".

Ao indagarmos sobre o Conselho Escolar, nenhum dos segmentos demonstrou saber como é o seu funcionamento na escola pesquisada. Uma das mães relatou, inclusive, que fazia parte do Conselho, mas nunca foi convidada para participar das reuniões e que apenas foi chamada para assinar as Atas. Foi então perguntado à mãe como ela foi escolhida para participar do Conselho e ela afirmou ter sido convidada pela direção da escola. O mesmo fato foi relatado por uma das funcionárias que também disse ter sido convidada para fazer parte do Conselho sem nunca ter participado de nenhuma reunião.

No que diz respeito ao PPP, apenas os professores disseram saber o que é o documento, mas, ao mesmo tempo, reconheceram que conhecem muito pouco de seu conteúdo, devido ao pouco tempo que dispõem para entrar em contato com outros trabalhos na escola além da sala de aula. Neste momento, um dos professores afirmou que já havia consultado este documento e observou que ele não é cumprido, principalmente no que diz respeito aos problemas relacionados à indisciplina dos alunos. Neste momento, percebemos que o professor não sabia diferenciar PPP do Regimento Escolar. Com relação ao Regimento Escolar, na opinião de funcionários e professores ele deveria ser revisto, pois "existe no papel", mas "não resolve os problemas da escola". Uma mãe relatou que não conhece o Regimento da Escola e que, no momento da matrícula, os pais recebem apenas um pequeno papel onde estão colocados os "deveres dos alunos", mas não conhecem, de fato, quais são as normas gerais.

Por fim, no que diz respeito à autonomia, os professores consideraram ser fundamental para o exercício da gestão democrática, mas afirmaram não haver, de fato, espaço para seu exercício, uma vez que são obrigados a "cumprir as ordens da Secretaria da Educação", ainda que essas ordens não considerem a realidade escolar.

\section{DISCUSSÃO}

Os relatos brevemente apresentados nos permitem considerar que a consolidação da gestão democrática ainda é um grande desafio a ser enfrentado pela escola estadual em questão. Embora a pesquisa não permita generalizações, o caso analisado corrobora com uma série de outras pesquisas já desenvolvidas (OLIVEIRA, 2015; RUELA FILHO, 2015; QUEIROZ, 2016) e demonstra que ainda há um longo caminho a ser percorrido no sentido de promover espaços de participação e decisão coletiva no âmbito escolar.

Em recente artigo publicado por Licínio Lima (2018), o autor ensaia uma resposta à questão "Por que é tão difícil democratizar a gestão da escola pública?". Tomando como referência diversos estudos, o autor esclarece que a resposta à referida questão não é única, mas aponta alguns caminhos que podem ajudar a compreender alguns pontos que caracterizam este fenômeno. O primeiro, diz respeito à resistência para democratizar a gestão das organizações advinda do longo período ditatorial que marcou a história de diversos países, incluindo o Brasil. 0 segundo ponto se refere à postura legalista que considera a mera aprovação do princípio democrático de gestão em lei suficiente para estabelecer modelos de gestão mais abertos à participação dos cidadãos sem que sejam avaliadas as devidas condições para sua efetivação nos espaços escolares. Por fim, os empecilhos impostos pelas circunstâncias atuais de reformas educativas de inspiração neoliberal que, numa perspectiva claramente gerencialista, incentivam a competitividade e a busca por resultados impostos pelo sistema, enfraquecendo a autonomia das instituições e a cooperação em busca de projetos educacionais mais alinhados às demandas locais.

Neste sentido, os dados demonstram que, diante da atual forma de organização dos sistemas de ensino, ancorada em uma lógica de responsabilização e meritocracia, a adoção da gestão democrática como princípio em lei não é capaz de democratizar a escola. Antes, é 
necessária uma reforma do próprio sistema, por meio de políticas públicas que garantam a participação da comunidade escolar em sentido amplo.

\section{CONCLUSÕES}

Neste artigo, apresentamos alguns dados de uma pesquisa desenvolvida em uma escola pública estadual, cujo objetivo era identificar os desafios enfrentados pela escola no processo de consolidação da gestão democrática; e compreender como esses desafios poderiam ser superados na percepção dos sujeitos que compõem o universo escolar. Os dados da pesquisa, obtidos por meio do diálogo com pais, alunos, professores, funcionários e gestores, revelaram como principais desafios a serem enfrentados a ausência de reflexão em torno do conceito de gestão democrática, a ausência de autonomia dos profissionais da educação frente às demandas da Secretaria Estadual, a ineficiência do Conselho Escolar formado por membros que não atuam de fato nos processos de tomada de decisões e o desconhecimento e a fragilidade dos documentos normativos internos, como o PPP e o Regimento Escolar, elaborados apenas para atendimento das exigências burocráticas, portanto, sem amplo diálogo com os diversos segmentos da escola de maneira que todos pudessem traçar caminhos mais viáveis para a abertura de novos canais de participação em atendimentos aos princípios democráticos.

\section{REFERÊNCIAS}

ANDRÉ, Marli E. D. A. Pesquisa no Cotidiano Escolar. In: FAZENDA, Ivani. (org.). Metodologia da Pesquisa Educacional. 10aㅡ. ed. São Paulo: Cortez, 2006.

DUARTE, Newton. Educação Escolar, teoria do cotidiano e a escola de Vigotski. 4a ed. Campinas: Autores Associados, 2007.

BOURDIEU, Pierre; PASSERON, Jean Claude. A Reprodução: elementos para uma teoria do sistema de ensino. 4aa ed. Petrópolis, RJ: Vozes, 2011.

LIMA, Licínio C. Por que é tão difícil democratizar a gestão da escola pública? Educar em Revista, Curitiba, Brasil, v. 34, n. 68, p. 15-28, mar./abr. 2018. https://doi.org/10.1590/0104-4060.57479

MAIA, Graziela Z. Abdian. Análise documental e Análise de Conteúdo. In: MACHADO, Lourdes Marcelino; MAIA, Graziela Z. Abdian; LABEGALINI, Andréia C. F. Baraldi. Pesquisa em Educação: passo a passo. Marília: Edições M3T Tecnologia e Educação, 2007.

OLIVEIRA, André Luiz Regis de. Entre a escola e a família: nuances de um (des)encontro. 2015. 158 f. Dissertação (Mestrado em Educação) - Programa de Pós-Graduação em Educação, PUC, Rio de Janeiro: RJ, 2015.

QUEIROZ, Benedito José de. Gestão Democrática escolar: uma imersão nos contextos cotidianos. 2016. 157 f. Dissertação (Mestrado em Educação) - Programa de Pós-Graduação em Educação, UERN, Natal: RN, 2016.

PARO, Vitor H. Administração Escolar: introdução crítica. 15a ed. São Paulo: Cortez 2008.

PARO, Vitor H. Crítica da estrutura da escola. 2a ed. São Paulo: Cortez, 2016.

RUELA FILHO, Maria. Democracia decretada e participação praticada: desafios e possibilidades da gestão escolar democrática em uma escola municipal de Poços de Calda - MG. 2015. 160 f. 
Dissertação (Mestrado em Educação) - Programa de Pós-Graduação em Educação, UNIMEP, Piracicaba: SP, 2015.

SAVIANI, Demerval. Escola e Democracia. Edição Comemorativa. Campinas: Autores Associados, 2008. 